(C) 2017 IEEE. Personal use of this material is permitted. Permission from IEEE must be obtained for all other uses, in any current or future media, including reprinting/republishing this material for advertising or promotional purposes, creating new collective works, for resale or redistribution to servers or lists, or reuse of any copyrighted component of this work in other works. 


\title{
A Low-Cost and Novel Approach in Gearshift Control for a Mild-Hybrid Powertrain
}

\author{
Mohamed Awadallah ${ }^{1}$, Peter Tawadros ${ }^{2}$, Paul Walker ${ }^{3}$, Nong Zhang ${ }^{4}$ \\ ${ }^{1}$ School of Electrical, Mechanical and Mechatronic Systems, University of Technology Sydney - UTS \\ Mohamed.M.Awadallah@student.uts.edu.au¹, eng.m.zakaria@gmail.com¹,Peter.Tawadros@uts.edu.au², \\ Paul.Walker@uts.edu.au ${ }^{3}$, Nong.Zhang@uts.edu.au ${ }^{4}$
}

\begin{abstract}
A novel, the low-cost mild hybrid powertrain is described. It relies on a manual, or robotized manual transmission together with a BLDC motor coupled at the output for filling the torque hole between gear changes. In order to keep manufacturing cost low and improve commercial attractiveness, it incorporates gearshift strategies that deliver high-quality gear shifts. A deliberate downsizing of componentry is implemented as far as possible to reduce cost, and control strategies are employed to exploit the maximum potential of the architecture using methods including torque-fill, ICE-assist, and ICE start-stop. The architecture is developed in simulation using an existing conventional platform to investigate system properties and their effect on performance. In particular, we discuss the gear-shift control algorithm design. Until the cost of full hybrids and fuel cell vehicles is significantly reduced, such a mild hybrid may have the potential to provide the right cost-benefit balance to achieve strong market penetration.
\end{abstract}

Keywords- Manual transmission; Mild HEV; Shift quality; Simulation; Torque hole; Vehicle;

\section{INTRODUCTION}

A mild hybrid electric powertrain equipped with an automated manual transmission (AMT) or manual transmission (MT) represents the greatest opportunity for improvement of driving comfort, shifting quality and improved driveability at the lowest possible manufacturing and ownership cost. It is our goal to develop a proof-ofconcept of such a vehicle, to increase the market penetration of hybridization in developing countries, where, it can be confidently argued, such technology is most needed. Herein, we briefly discuss the commercial and social role of a vehicle of this type and detail the development of a gear-shift control strategy for our vehicle.

Modern hybrid powertrains aim to deliver excellent ride quality and high efficiency through smooth tractive torque delivery [1]. To this end, some powertrains employ continuously variable transmissions, eliminating shift transients, but introducing other limitations and increasing cost. Good system design can maximise efficiency and ride quality, but it is the powertrain control systems which must provide optimal control of transmission and engine speeds and torques to achieve the best possible results during the transient (shift) periods. Powertrain transient vibration during and after gearshift are the results of discontinuities in torque, speed, and inertia (typically resulting from ratio change and power decoupling). Transient control of the powertrain aims to reduce these discontinuities to a minimum so as to restrict the dynamic response to desirable levels [2]. The mild hybrid structure used in this paper employs a low voltage electric motor coupled to the transmission output shaft. Input signals for motor control include (i) clutch position, (ii) ICE load (typically from engine map), and (iii) engaged gear. The electric motor achieves three outcomes. First, it should minimise the torque hole during gear shift by supplying an output torque to the wheels when the clutch is open. Second, it should provide some capacity for damping out torsional vibration during launch and gear change. Third, it will assist the ICE during launch and provide some regenerative braking capacity during braking [3]. In the remainder of the paper the role of integrated powertrain control for gear change is discussed, then a methodology for achieving high-quality shift control is presented, aimed at minimising this torque hole. Last, simulation results are presented and conclusions drawn from these results.

\section{A. Shift Process Analysis}

Analysis of the shift process is essential for ensuring shift quality control. It requires release and re-engagement of a single friction clutch between the prime mover and transmission. Within this, there are additional phases. First, there is the clutch disengagement. Disengagement is characterised by a rapid reduction in torque to the transmission as the prime mover is isolated. Second gear selection occurs. With the clutch open, alternative synchronizers are released and engaged to select the target gear. At this point, there is no traction load to the road, and a substantial torque hole is generated. There can also be some transient response as synchronizers are released and engaged. Finally, there is the inertia phase. It involves friction loading of the clutch to synchronise speeds and is characterised by large torsional vibrations during clutch slip and lockup. When speeds are synchronised lockup is achieved, and the clutch is fully engaged. There are many factors that impact on the shift process, such as the magnitude of transmitted torque before and after the gear change, and the rate of clutch disengagement and engagement. Fig. 1 shows actual vehicle output shaft torque with partial torque fill during shifting [4].

\section{HYBRID ELECTRIC POWERTRAIN}

Fig. 2 presents the layout of a mild hybrid, manual transmission equipped powertrain. The nature of the powertrain requires a single dry-plate clutch interfacing between the engine and transmission. System damping can be identified from a few different sources. These sources include 


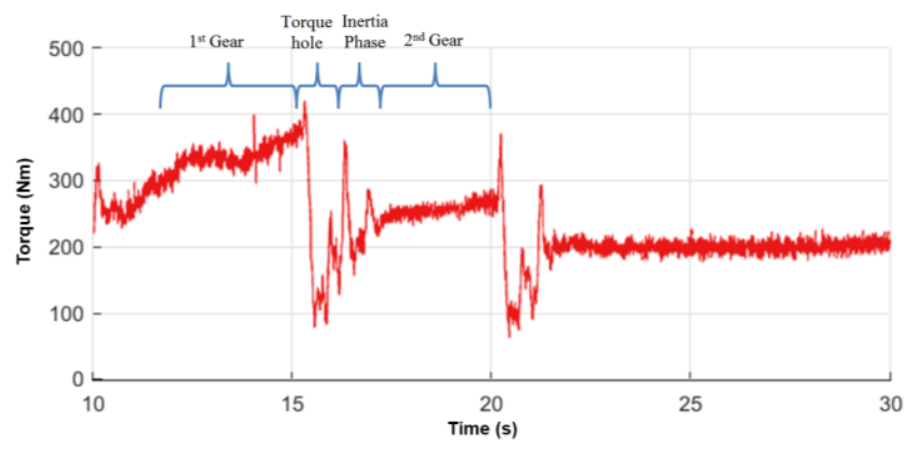

Fig. 1. Actual Half-shaft torque with Fill-in

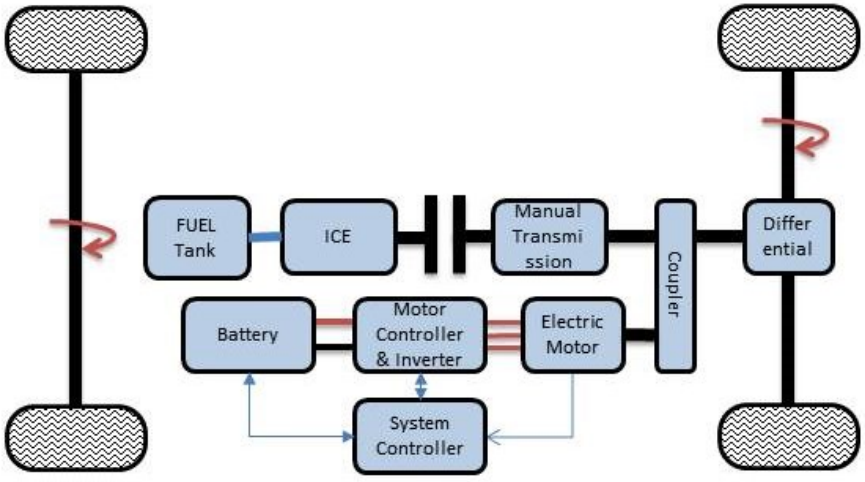

Fig. 2. General Powertrain layout with hybridisation.

torsionally-mounted coil springs within the clutch disc assembly, as well as damping resulting from viscous friction in the engine and transmission [5]. A pre-tensioned (normally closed) diaphragm spring clamps the clutch disc to the engine output, and the friction plate is independently splined to the transmission input shaft. In this model gears, one to five are connected to the input and output shafts, where they can be individually selected with synchronizer mechanisms, and are driven through the closed clutch. In a traditional manual transmission, the primary clutch is opened before synchronisation, isolating the synchronizer from engine inertia and torque. Also shown in Fig. 2 is the remainder of the powertrain, including the electric machine (EM) that is coupled to the transmission output shaft, and directly drives the wheels through a fixed gear ratio. Such a configuration is typically defined as a post-transmission parallel-type hybrid vehicle powertrain. A previous design study has shown that the electric machine requirements for this application may be most suitably met by a Brushless DC Motor (BLDC), rated at $10 \mathrm{~kW}$ continuous mechanical power. BLDCs have been widely used in HEV and EV applications [6-8]. The results of the aforementioned study demonstrated that a $10 \mathrm{~kW}$ electric machine was capable of partially satisfying the majority of the requirements for torque-fill in during gear change, while still having sufficient power to be able to have a positive effect on the vehicle driving efficiencies under the target conditions of high demand or low engine efficiency.

The role of the powertrain is to deliver torque to the road over a large range of operating speeds. Therefore, the driving torque, gear reduction, and vehicle resistance torque must be considered to model the powertrain effectively. The powertrain is a simple post-transmission parallel hybrid configuration. It utilises a low-powered four-cylinder engine coupled to a five-speed manual transmission through a robotically actuated clutch. A motor is connected to the transmission output shaft, before the final drive. The literature includes some similar architectures to that proposed herein [911]. Of these, Baraszu [9] most closely resembles the architecture proposed herein. However, our proposed architecture is simpler still, by the omission of the motor clutch. Moreover, the primary focus of our research is as much about the socio-environmental impact of the technology as it is on the technical development. Our project constraints are derived from the fundamental goal of bringing hybrid technology to developing nations with high mortality rates attributed to environmental pollution. This focus compares with the literature, which typically focuses on the technological aspect without significant reference to its social context. The system dynamics and modelling constraints of this mild hybrid electric powertrain have been previously disclosed in papers by our research group, published in [1214]

\section{COST ANALYSIS}

Transportation is responsible for some $70 \%$ of petroleum consumption globally. Moreover, demand is projected to increase by $50 \%$ from 2009 to 2030 [15]. One useful approach to assessing longer-term strategic options is to project the potential of the propulsion system and vehicle technical improvements to reduce fuel consumption. Powertrain technologies currently under development typically involve some level of electrification, but still face technical challenges before they can be considered market competitive [16]. Our goal is to develop an ultra-low-cost electric hybrid drive system for small vehicles as a proof of concept exercise. Our low-cost drive system is designed primarily for developing markets, due to the correlation these markets have with high atmospheric pollutant levels $[17,18]$. We develop our hybrid vehicle with the goal of approaching drive characteristics (in particular, shift characteristics) of an automatic vehicle, using low-cost hardware. A 5\% cost limit on the net manufacturing cost increase of the base vehicle is a primary design criterion. This value has been chosen as being representative of the typical variation that may be acceptable to the end consumer. The value covers the total cost of hybridization, included motor, inverter, and battery. By minimising added cost to the vehicle, we ultimately make the vehicle more likely to be appealing to the consumer in these regions. Clearly, any increase in cost over the cost to produce the equivalent ICEpowered vehicle must be compensated through other means, such as fuel or tax savings.

\section{A. Electric propulsion system (EPS)}

Without final designs, accurately estimating manufacturing cost is difficult. Various methods have been proposed for approximating the manufacturing cost based on physical performance requirements. McKeever [19] gives original equations (1), (2) for both the inverter and motor cost, however, because of the technological and scale 
improvements in the intervening period, they cannot be considered realistic in the current term.

$$
\text { Inverter cost }=\$ 418+\$ 7.60 \times \mathrm{kW} \text { peak }
$$

$$
\text { Motor Cost }=\$ 33.33+\$ 10.6 \times \mathrm{kW} \text { peak }
$$

Hadley [20] proposes a near-term cost of US $\$ 41$ per rated $\mathrm{kW}$ for total motor and inverter cost. $\mathrm{Wu}$ [21] provides a compound annual growth rate (CAGR) for the capital cost of HEV components. For the motor/controller, the CAGR is $4.4 \%$. By applying the CAGR to the figure proposed by Hadley [20], we arrive at a 2016 figure of US $\$ 31.30 / \mathrm{kW}$. Our motor and controller are therefore expected to add approximately US\$375.60 to the cost of the base vehicle.

\section{B. Battery}

In determining the battery capacity and size, the intent of the mild hybrid is to provide some of the benefits of hybrids at a low incremental cost. This intent is accomplished using a small battery pack [22, 23]. Battery sizing may be calculated by assuming the vehicle is only operating in charge-sustaining mode. Charging is accomplished by selecting optimum times to run the engine at a higher load point than road-speed requires, using the excess power to drive the BLDC motor. $80 \%$ of the battery capacity is assumed to be available for tractive power. The component efficiency of the system was previously calculated at $85 \%$ for the motor and controller [24, $25]$, and $81 \%$ coulombic efficiency was estimated. Multiplying these figures results in $69 \%$ total efficiency applied to both the charge and discharge cycles. Battery sizing is calculated using a discharge rate of $15 \mathrm{C}$ and a charge rate of $10 \mathrm{C}$, both of which are within the capabilities of typical $\mathrm{NiMH}$ batteries. A tractive power demands of $10 \mathrm{~kW}$ maximum results in a required battery capacity of $0.968 \mathrm{kWh}$ to achieve $15 \mathrm{C}$ discharge. Using the NYC cycle, a maximum required regenerative braking power of $9.2 \mathrm{~kW}$ is calculated. The latter figure results in a required battery capacity of $0.633 \mathrm{kWh}$ for charging at $10 \mathrm{C}$. The larger calculated value should prove sufficient to power the vehicle under ideal conditions, but nominally $1.2 \mathrm{kWh}$ is used, to account for temperature effects and other losses in the absence of battery model specifications.

The hybrid drive system is being developed with the ultimate goal of ensuring that any extra cost of the system should not exceed $5 \%$ over the expense of the base vehicle as manufacture cost for hybridization to include motor, inverter, and battery. This figure is the price point at which the mild hybrid architecture proposed will make immediate business sense from a consumer perspective. From [23], we approximate the cost of a $1.2 \mathrm{kWh}$ battery to be US\$60. This cost yields a total system cost of US\$435.60. Our system is designed to be suitable for mass-market vehicles sold in premature stage markets and serves both to improve ambient air pollution characteristics, which are typically poor owing to urban particulate matter [26], as well as reduce fossil-fuel dependency in these regions. Because of the price sensitivity of these markets, at costs above the upper limit specified, further justification is necessary. Further investigation is required in the area of cost-reduction to reach and exceed this goal.

\section{SHIFT-CONTROL STRATEGIES FOR MILD HEV}

Gear shift control has many parameters that affect its implementation. Hardware that could be used to improve control includes a robotized clutch and gear actuator, by controlling target gear and shift time. To effectively come up with enhancements to a control system, one must not exclude the influences of the clutch, throttle position, engine, prop shaft speed and gear state. Driver-in-loop or open-loop electronic control provides a cost-effective and faster method of application to a robotized system, as well as yielding valid output. A known drive cycle would be used as a predictive model to show proof of concept. The integration of a robotized gear and clutch actuator is assumed in regards to shift-control strategies mentioned. The motor assembly integrated into the transmission output shaft would be driven by a control unit, which is fed information on gear state and clutch engagement. There are three different phases of control implemented in the system. The first of these is ICE-start, which is necessary for starting the vehicle from a resting state. The others are shift-up and shift-down respectively, both sharing similar processes. The ICE-start phase can be implemented in three ways: by the engine, the motor, or both simultaneously. When starting with engine alone, the first gear is engaged, and the clutch is open. This condition results in no transference of torque to the wheels. A progressive torque transfer to the gear set of the first gear when the clutch begins to engage, which is due to an axial load influencing the clutch's friction surface. At this point, the system can permit control for the shift-up phase.

Certain situations influence the method of implementing ICE-start. Suitably high-SOC, the cessation of the engine by idle start-stop and low torque request by the driver allow for ICE-start by motor alone. The second gear is engaged in this process, with the clutch open so that the motor does not drive the engine. All of the necessary torque is provided by the motor until a scheduled shift into second gear is needed or the engine fires due to a low-SOC. At engine firing, the system implements the shift-up mode with the appropriate gear preselected for engagement. In a situation where a request for high torque is demanded by the driver, both engine and motor can propel the vehicle from rest in ICE-start. To allow for swift progress while maximising driveability, the 1-2 torque hole may be minimised by operating the motor at peak torque until after the 1-2 shift is completed. This strategy is preferred because, at high torque, the motor is incapable of completely filling the 1-2 torque hole.

Fig. 3 outlines the process involved in shift-up. This regime is applicable when a shift higher from the currently selected gear is needed. Along the same principle, shift-down is utilised in the selection of a lower gear than the currently selected one. Fig. 4 visualises a shift schedule which determines the implementation of either the shift-up or shiftdown phases [27]. The torque hole compensation function can be developed in the absence of robotized gear, and clutch actuation as the proof-of-concept will be demonstrated in relation to specified drive cycles; target torques and speeds can be programmed and the control strategy implemented 

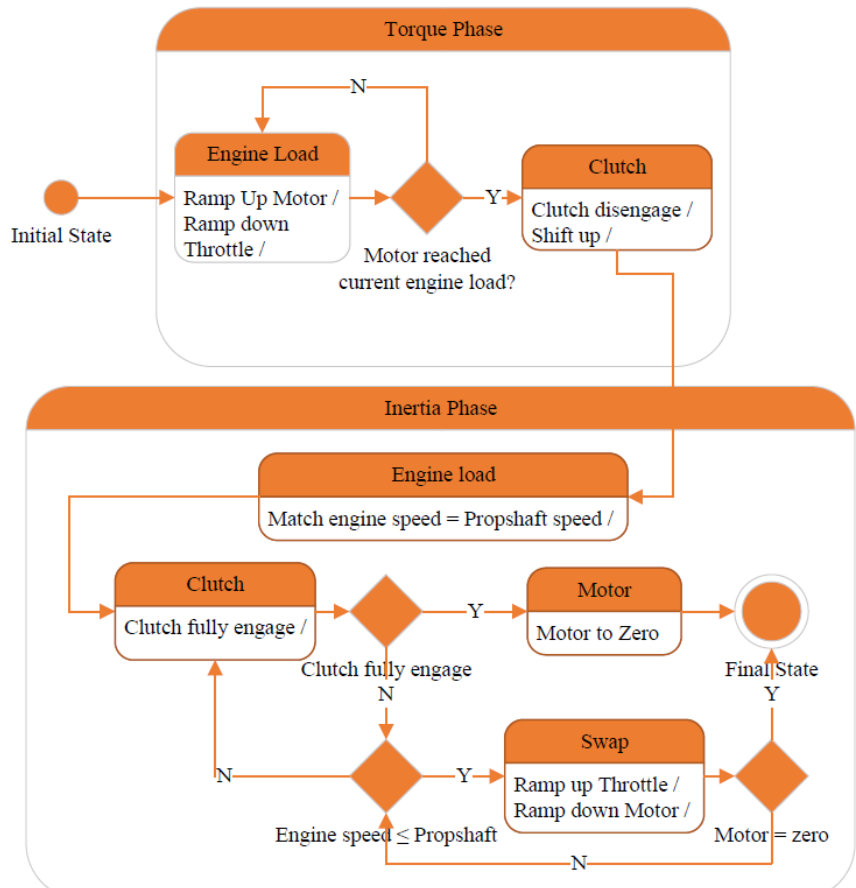

Fig. 3. Up-shift process.

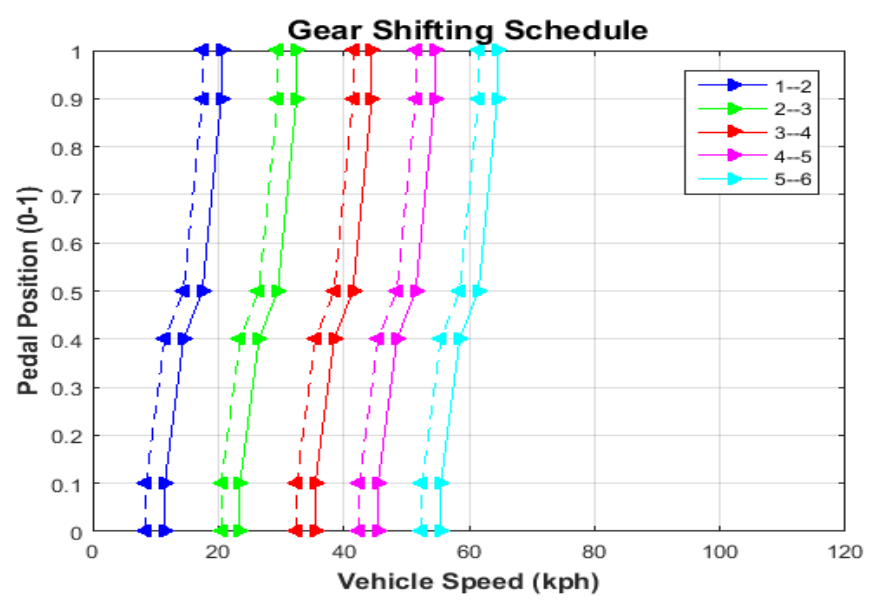

Fig. 4. Gear Shifts schedule.

using a clutch switch. This prospect allows for a cost-effective method of studying system performance with and without automatic shifting. Manual transmission synchronizers are used to match speeds with the target gear and physically lock it to the shaft. These are made up of a dog-clutch and a cone. The cone raises the gear to the speed of the shaft, after which the dog-clutch is engaged. This method can compensate for the typical dynamic limits of manual transmission [28], so that as each gear is engaged the need for acceleration is reduced. Considering an ideal implementation of this, along with continuous torque transmissions during gear shifts, would see no loss of tractive load to the road with minimal observed torque. The resulting observation would be an improvement in performance and driving comfort. However, to ensure optimum driveability (vibration) and performance, the consideration of time delays implemented in shift control is vital.

Control block diagrams developed in Simulink are representative of the developmental work on shift control. These can be seen in the appendix. The theoretical framework mentioned earlier is actualised in the Stateflow chart Fig. 10, which contains two important differences; A grouping of the shifting processes states together to form the "SelectionState" superstate, and the gear states to form the "GearState" superstate respectively. This organizational form helps arrange the mode logic into a hierarchal structure which allows for clearer illustration and diagnosis.

\section{Simulation}

Model simulation proves essential for observing and improving the performance of hybrid electric vehicles, among others. This method has gained the attention of industry and academics alike to validate and calibrate certain systems. The platform for the conducted simulations was the Matlab/Simulink environment, within which the discussed powertrain model was built as a mild HEV model. The simulation operates in a way that would be the opposite of what would be observed in a real-world application; the drive cycle itself provides the input data to the vehicle model. Based on this data, a determination of the changes in vehicle speed is calculated in regards to the drive cycle. The current gear ratio (with a provided shifting map to the model) along with the efficiencies of the transmission are considered when the alteration to vehicle speed is converted to engine speed and relevant torque requirements. The electric drive mode part, along with an evaluation of the transient response of the drivetrains are the main focal points in the results. Error! Reference source not found. outlines the vehicle parameters which were used in the model.

\section{A. Engine and motor model}

The physical simulation models of the engine, motor, and control system were established based on the Simscape environment. The engine model only plays a role in providing torque output and speed for a given throttle command, so the simple engine model "Generic Engine" in the Simdriveline is chosen directly, such as is used in [27, 28]. The physical simulation models of the EPS (motor and control) were also established in the Simscape environment. Generally, to reduce the computational demand for simulations, EPS models use an integrated efficiency map, requiring only a maximum output torque and the battery power to determine the driving load delivered to the wheels. Look-up tables may be used to find directly the output torque, based on a given throttle commands and motor speed. The look-up table used in the model presented is obtained from ADVISOR and is based on the Unique Mobility $10 \mathrm{~kW}$ BLDC motor. Fig. 5 shows the SIMULINK implementation of motor [29, 30]. For the EPS it is assumed that the demanded power from the controller is supplied to the motor, this is combined with motor speed and 
efficiency to determine the actual motor output torque.

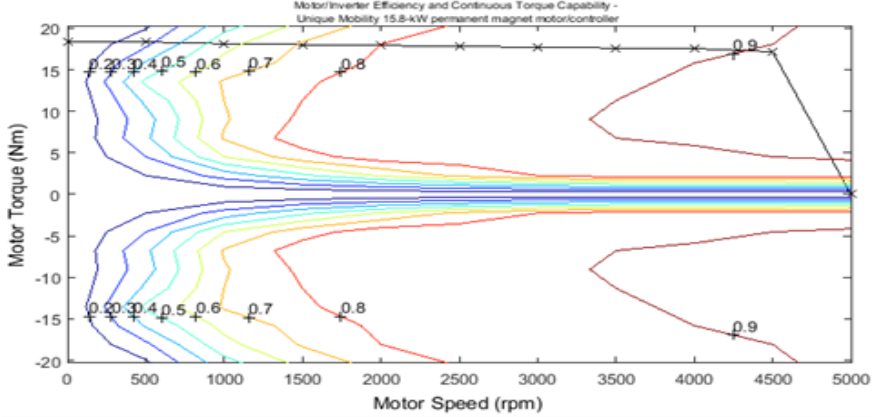

Fig. 5. BLDC Model in SIMULINK.

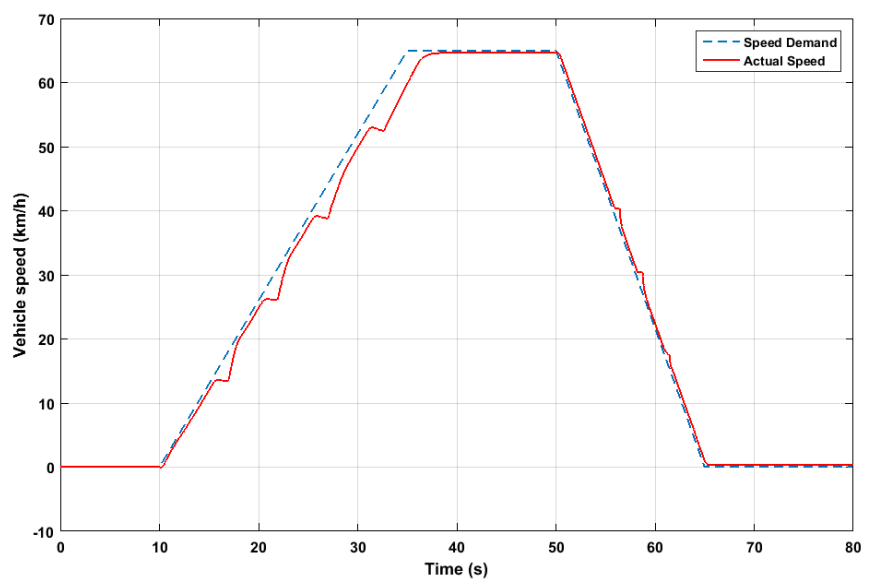

Fig. 6. Manual Transmission RDC speed profile.

The Rural Driving cycle (RDC) Fig. 6 was used to compare data initially. The RDC is a dynamometer drive schedule that is used to benchmark vehicle performance in a controlled manner. The RDC does not include any simulated incline changes and is intended to test a vehicle as it might perform in a rural setting. It was selected as an initial benchmark for its simplicity and its ability to highlight gear shift characteristics consistently. It features a single acceleration event, a cruise, and a deceleration and utilises five up-shifts over its duration. Each up-shift results in a large hole in the output torque and decreasing acceleration. By applying motor torque to the final drive and ensuring that the clutch pressure stays applied throughout the control process, the torque hole may be filled to varying degrees. Simulations yielded results showing this effect using both a conventional and a torque-fill powertrain. By comparing the results, we show the difference in magnitude of the torque hole, as well as improvement in acceleration and transient behaviour between the different powertrains. The results shown in Fig. 6 describes the variation in shaft speed due to different gear ratios and compare the transient response.

Fig. 7 represents the output shaft torque of the conventional and torque-fill drivetrain when upshifting from $3^{\text {rd }}$ to $4^{\text {th }}$ gear.
Fig. 8 shows the velocity of the vehicle during an acceleration event $0-100 \mathrm{~km} / \mathrm{h}$. For a fixed throttle angle profile, the acceleration time is reduced by approximately 1.5 seconds using the torque-fill drivetrain, and the deceleration at each gear shift is reduced markedly.

Fig. 9 describes the torque developed at the output shaft of both modelled drivetrains during an upshift sequence from 2 nd to 5 th gear. Three discrete torque oscillation responses are evident in each upshift event.

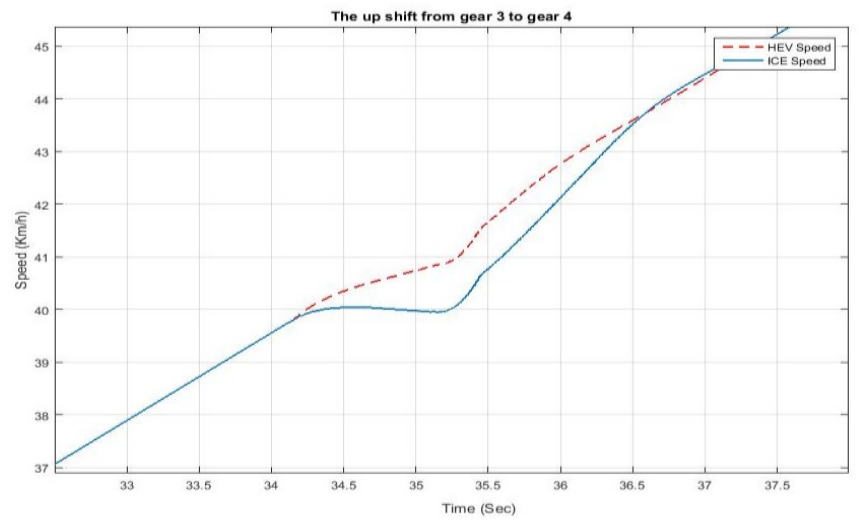

Fig. 7. Shift process analysis.

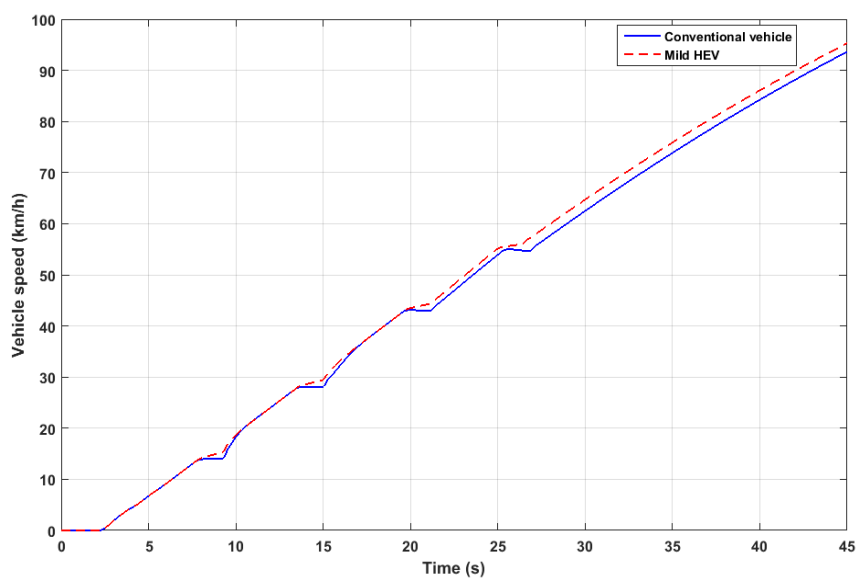

Fig. 8. Speed profile in ICE and Mild HEV models.

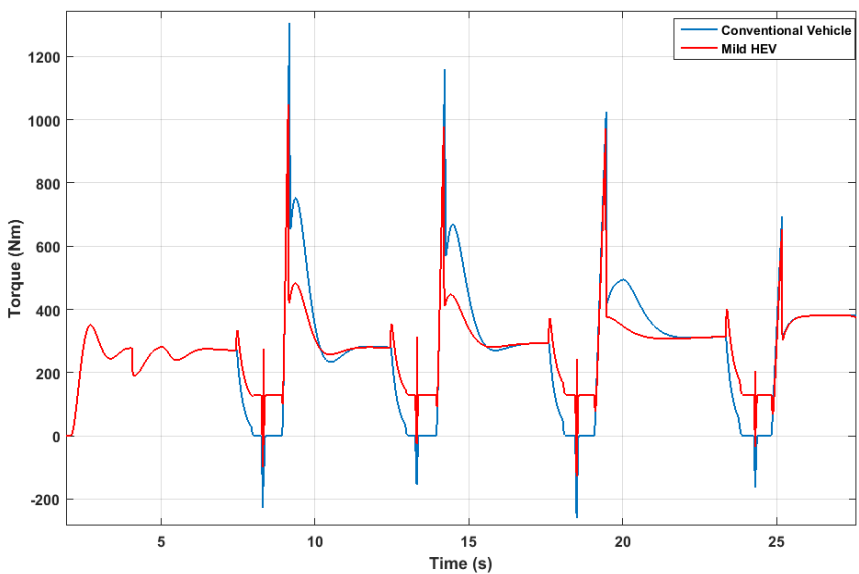

Fig. 9. Torque profile. 
The first is caused by clutch disengagement. The decoupling of the engine and flywheel inertia from the transmission causes a torque excitation response. The second oscillation of lesser magnitude is caused by gear synchronisation, which involves the desynchronization of the previous gear, and the selected gear to be locked to the output shaft. The change in gear ratio requires a sudden speed variation. The third oscillation is a result of clutch re-engagement. The third oscillation is characterised by torque overshoot due to angular velocity variation at the torque interface (flywheel and clutch) [31]. The effect of this response at the output shaft is illustrated clearly. By way of comparison, it is shown clearly that the torque-fill mode of operation significantly reduces the magnitude of the torque hole, as well as causing a 175 N.m. reduction in the peak magnitude of torque oscillation.

\section{CONCLUSION}

The mild hybrid powertrain discussed herein is a low-cost option developed for implementation in highly price-sensitive markets. The development work presented, including the development of the physical system specifications, as well as the control and simulation discussed arises out of the need to deliver a suitable option for pre-mature markets that do not yet support significant electrification. This paper has introduced a powertrain concept incorporating a manual transmission and a low-power BLDC electric motor, the aim of which is to deliver superior drivability and comfort, improved emissions and performance over conventional powertrains. The predominant method for these gains is by delivering fill-in torque during gear shifts.

The 5MT was selected because it offers much lower manufacturing cost, much higher transmission efficiency, and much higher in-service reliability than CVT. This is particularly important in our target market which is pricesensitive and in which fleet age is relatively higher than western markets. A strategy for up-shifting is presented, utilising the hybridised powertrain to decrease the torque hole. The torque fill drivetrain may be applied equally successfully to both AMT and MT gearboxes. The cost of the system is limited by the deliberate downsizing of the continuous motor power, and the simultaneous reduction in duty cycle to allow the possibility of safe momentary overload if required, yielding greater benefit. The flow-on effect of this is that other components, such as batteries, converters, and power electronics are also positively limited in size and cost. Future research at the University of Technology Sydney will further develop, implement, validate and report on these control strategies in experimental facilities.

\section{APPENDIX}

TABle I. Vehicle Global Specifications

\begin{tabular}{|l|l|l|}
\hline Component & \multicolumn{1}{|c|}{ Parameter } & \multicolumn{1}{c|}{ SI Units } \\
\hline \multirow{5}{*}{ Engine } & Type & Spark-Ignition \\
\cline { 2 - 3 } & Maximum power & $70 \mathrm{~kW}$ \\
\cline { 2 - 3 } & Maximum speed & $7000 \mathrm{rpm}$ \\
\cline { 2 - 3 } & $\begin{array}{l}\text { Speed at maximum } \\
\text { power }\end{array}$ & $5500 \mathrm{rpm}$ \\
\cline { 2 - 3 } & Cylinders & 4 \\
\hline
\end{tabular}

\begin{tabular}{|c|l|l|}
\hline \multirow{4}{*}{ Vehicle } & Idling speed & $800 \mathrm{rpm}$ \\
\cline { 2 - 3 } & Mass as hybrid & $1200 \mathrm{~kg}$ \\
\hline & Drag coefficient & 0.4 \\
\cline { 2 - 3 } & Frontal area & $3 \mathrm{~m} 2$ \\
\cline { 2 - 3 } & CG to rear axle distance & $1.6 \mathrm{~m}$ \\
\cline { 2 - 3 } & CG to front axle distance & $1.4 \mathrm{~m}$ \\
\cline { 2 - 3 } & Tire rolling radius & $0.312 \mathrm{~m}$ \\
\cline { 2 - 3 } & CG height & $0.5 \mathrm{~m}$ \\
\hline \multirow{3}{*}{$\begin{array}{c}\text { Mear ratio } \\
\text { MHEV) }\end{array}$} & First to Fifth & $3.581,2.022,1.4,1.03,0.94$ \\
\cline { 2 - 3 } & Final drive ratio & 4.06 \\
\cline { 2 - 3 } & Voltage & $96 \mathrm{~V}$ \\
\cline { 2 - 3 } & Maximum power output & $10 \mathrm{~kW}$ \\
\cline { 2 - 3 } Battery & Maximum torque & $54 \mathrm{Nm}$ \\
\hline & Type & NiMH \\
\cline { 2 - 3 } & Capacity & $1.2 \mathrm{kWh} / 12.5 \mathrm{Ah}$ \\
\cline { 2 - 3 } & Discharge/Charge rate & $15 \mathrm{C} / 10 \mathrm{C}$ \\
\hline & & \\
\hline
\end{tabular}
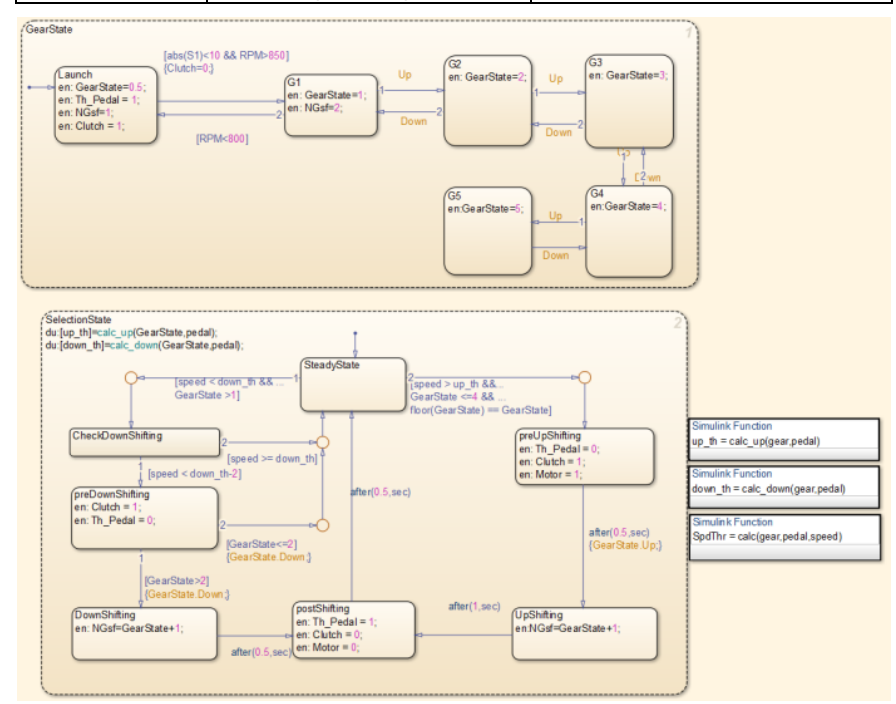

Fig. 10. Manual transmission logic modelled with Stateflow (shift state).

\section{REFERENCES}

[1] K.-L. Kuo, "Simulation and Analysis of the Shift Process for an Automatic Transmission," World Academy of Science, Engineering and Technology, vol. 52, pp. 341-347, 2011.

[2] Z. Sun and K. Hebbale, "Challenges and opportunities in automotive transmission control," in American Control Conference, 2005. Proceedings of the 2005, 2005, pp. 3284-3289.

[3] G. Wagner, "Application of transmission systems for different driveline configurations in passenger cars," SAE Technical Paper2001.

[4] R. C. Baraszu and S. R. Cikanek, "Hybrid electric vehicle with motor torque fill in," in Ford Motor Company, ed: Google Patents, 2003.

[5] A. Serrarens, M. Dassen, and M. Steinbuch, "Simulation and control of an automotive dry clutch," in American Control Conference, 2004. Proceedings of the 2004, 2004, pp. 4078-4083.

[6] M. Zeraoulia, M. E. H. Benbouzid, and D. Diallo, "Electric motor drive selection issues for $\mathrm{HEV}$ propulsion systems: A comparative study," Vehicular 
Technology, IEEE Transactions on, vol. 55, pp. 1756-1764, 2006.

[7] S. Sharma and V. Kumar, "Optimized Motor Selection for Various Hybrid and Electric Vehicles," SAE Technical Paper2013.

[8] L. Chang, "Comparison of AC drives for electric vehicles-a report on experts' opinion survey," Aerospace and Electronic Systems Magazine, IEEE, vol. 9, pp. 7-11, 1994.

[9] R. Baraszu and S. Cikanek, "Torque fill-in for an automated shift manual transmission in a parallel hybrid electric vehicle," in American Control Conference, 2002. Proceedings of the 2002, 2002, pp. 1431-1436.

[10] Z. Rahman, K. L. Butler, and M. Ehsani, "A comparison study between two parallel hybrid control concepts," Development, vol. 1, p. 0978, 2000.

[11] K. Aoki, S. Kuroda, S. Kajiwara, H. Sato, and Y. Yamamoto, "Development of integrated motor assist hybrid system: development of the'insight', a personal hybrid coupe," Honda R and D Co., Ltd.(US)2000.

[12] M. Awadallah, P. Tawadros, P. Walker, and N. Zhang, "Eliminating the torque hole: Using a mild hybrid EV architecture to deliver better driveability," in 2016 IEEE Transportation Electrification Conference and Expo, Asia-Pacific (ITEC AsiaPacific), Busan, South Korea, 2016, pp. 173-179.

[13] M. Awadallah, P. Tawadros, P. Walker, and N. Zhang, "Comparative System Dynamic Modeling of a Conventional and Hybrid Electric Powertrain," in Power Engineering - International conference on Power Transmissions (ICPT 2016), Y. S. Datong Qin, Ed., ed Chongqing, China: CRC Press, 2016, pp. 231-238.

[14] M. Awadallah, P. Tawadros, P. Walker, and N. Zhang, "Dynamic modelling and simulation of a manual transmission based mild hybrid vehicle," Mechanism and Machine Theory, vol. 112, pp. 218239, June 20172017.

[15] A. MacKnight, "Engine an Innovation that Brings Improved Fuel Economy and a Reduced Carbon Foot print for Automotive Applications," in PRESENTED AT THE CLINTON GLOBAL INITIATIVE ANNUAL GENERAL MEETING, New York, USA, 2009.

[16] E. P. Kasseris and J. B. Heywood, "Comparative analysis of automotive powertrain choices for the next 25 years," SAE Technical Paper 0148-7191, 2007.

[17] K. R. Smith, "Fuel combustion, air pollution exposure, and health: the situation in developing countries," Annual Review of Energy and the Environment, vol. 18, pp. 529-566, 1993.

[18] D. Campbell-Lendrum and C. Corvalán, "Climate change and developing-country cities: implications for environmental health and equity," Journal of Urban Health, vol. 84, pp. 109-117, 2007.
[19] J. W. McKeever, S. Das, L. M. Tolbert, L. D. Marlino, and A. Nedungadi, "Life-Cycle Cost Sensitivity to Battery-Pack Voltage of an HEV," Life, vol. 1, p. 1556, 2000.

[20] S. W. Hadley and T. P. Cleary, "Plug-in Hybrid Electric Vehicle Value Proposition Study-Final Report," 2010.

[21] G. Wu, A. Inderbitzin, and C. Bening, "Total cost of ownership of electric vehicles compared to conventional vehicles: A probabilistic analysis and projection across market segments," Energy Policy, vol. 80, pp. 196-214, 2015.

[22] R. Sharma, M. Bessede, C. Manzie, M. Brear, and R. Crawford, "An economic and in-service emissions analysis of conventional, hybrid and electric vehicles for Australian driving conditions," SAE Int. J. Commer. Veh, vol. 5, pp. 291-298, 2012.

[23] P. Brown, N. Jackson, L. Sykes, J. Wheals, and M. Wiseman, "A Hybrid and Fuel Cell Vehicle Future?," SAE Technical Paper 0148-7191, 2002.

[24] M. Awadallah, P. Tawadros, and N. Zhang, "Rapid Prototyping and Validation of Mars 0913 Brushless Motor to Develop Mild HEV," in The 7th TM Symposium China (TMC2015), Shanghai, China, 2015, pp. 92-98.

[25] M. Awadallah, P. Tawadros, P. Walker, and N. Zhang, "Selection and Characterisation of PMSM motor for mild HEV Applications," in 29th Electric Vehicle Symposium 2016 (EVS29), Montréal, Québec, Canada, 2016, pp. 1276-1286.

[26] T. Hutchinson, S. Burgess, and G. Herrmann, "Current hybrid-electric powertrain architectures: Applying empirical design data to life cycle assessment and whole-life cost analysis," Applied Energy, vol. 119, pp. 314-329, 2014.

[27] J. Gong, D.-x. Zhao, Y. Chen, and N. Chen, "Study on shift schedule saving energy of automatic transmission of ground vehicles," Journal of Zhejiang University Science, vol. 5, pp. 878-883, 2004.

[28] G. Lucente, M. Montanari, and C. Rossi, "Modelling of an automated manual transmission system," Mechatronics, vol. 17, pp. 73-91, 2007.

[29] R. Johri and Z. Filipi, "Low-cost pathway to ultra efficient city car: Series hydraulic hybrid system with optimized supervisory control," 2010.

[30] C.-C. Lin, H. Peng, J. W. Grizzle, and J.-M. Kang, "Power management strategy for a parallel hybrid electric truck," Control Systems Technology, IEEE Transactions on, vol. 11, pp. 839-849, 2003.

[31] J. Fredriksson and B. Egardt, "Nonlinear control applied to gearshifting in automated manual transmissions," in Decision and Control, 2000. Proceedings of the 39th IEEE Conference on, 2000, pp. 444-449. 